\title{
Regnal Dates
}

\begin{tabular}{|c|c|}
\hline Richard II & $1377-1399$ \\
\hline Henry IV & $1399-1413$ \\
\hline Henry V & $1413-1422$ \\
\hline Henry VI & $1422-1461$ \\
\hline Edward IV & 1461-1470 \\
\hline Henry VI & $1470-1471$ \\
\hline Edward IV & $1471-1483$ \\
\hline Edward V & 1483 \\
\hline Richard III & $1483-1485$ \\
\hline Henry VII & $1485-1509$ \\
\hline Henry VIII & 1509-1547 \\
\hline Edward VI & $1547-1553$ \\
\hline Mary I & $1553-1558$ \\
\hline Elizabeth I & $1558-1603$ \\
\hline James I & $1603-1625$ \\
\hline Charles I & $1625-1649$ \\
\hline English Republic & $1649-1653$ \\
\hline Oliver Cromwell, Lord Protector & $1653-1658$ \\
\hline Richard Cromwell, Lord Protector & $1658-1660$ \\
\hline Charles II & $1660-1685$ \\
\hline James II & $1685-1688$ \\
\hline William III & $1689-1702$ \\
\hline
\end{tabular}



Permanent Revolution 
